\title{
Transcutaneous electrical stimulation and postoperative total knee arthroplasty pain
}

\author{
Mohamed N Mahomed MD, Gianni L Maistrelli MD FRCSC, Ayoob Mossanen MB ChB FRCPC, Derek Glazier PT
}

\begin{abstract}
MN Mahomed, GL Maistrelli, A Mossanen, D Glazier. Transcutaneous electrical stimulation and postoperative total knee arthroplasty pain.
\end{abstract}

Pain Res Manage 1998;3(2):101-104.

OBJECTIVE: To determine the efficacy of the Synaptic 2000 in reducing total knee replacement postoperative pain in a prospective randomized controlled trial.

DESIGN: Patients were prospectively randomly assigned to two groups, one receiving seven days of transcutaneous electrical stimulation (TES) therapy in addition to standard postoperative care, and the other receiving standard postoperative care. Both groups received postoperative patient-controlled analgesia and were switched to oral opiates.

SETTING: Patients were treated at a university teaching hospital for elective primary unilateral total knee replacement.

PATIENTS: All patients consented to enter the study. All had primary osteoarthritis. Fifteen patients were entered into each arm of the study, and all patients completed the study. The mean age of patients was 64 years for treatment and 71 years for controls.

OUTCOME MEASURES: Outcome measures were analgesic consumption, return of knee range of motion and score on a visual analogue pain scale.

RESULTS: No significant differences were noted in postoperative analgesic use, knee range of motion, length of stay or visual analogue pain scale score. Mean total analgesic use of morphine was $148 \mathrm{mg}$ in the TES group and $108 \mathrm{mg}$ in the control group. The TES group mean knee range of motion on postoperative day 7 was $75.3^{\circ}$; it was $73.6^{\circ}$ in the control group. Group mean length of stay was 9.5 days in the TES group and 8.3 days in the control group.

Key Words: Pain, Postoperative care, Total knee replacement, Transcutaneous electrical stimulation

\section{Neurostimulation transcutanée et douleur post-opératoire après prothèse totale du genou}

OBJECTIF : Déterminer l'efficacité de Synaptic 2000 à soulager la douleur post-opératoire consécutive à une prothèse totale du genou dans le cadre d'un essai prospectif randomisé contrôlé.

MODÈLE : Des patients ont été aléatoirement randomisés en deux groupes, l'un devant recevoir pendant sept jour une neurostimulation transcutanée en plus des soins postopératoires habituels, l'autre, les soins postopératoires habituels seulement. Les deux groupes ont été placés sous auto-analgésie à la demande, puis sous opiacés par voie orale.

CONTEXTE : Les patients ont été traités dans un dans un centre hospitalier universitaire pour une première prothèse totale non urgente unilatérale du genou.

PATIENTS : Tous les patients ont accepté de participer à l'étude. Ils souffraient tous d'arthrose primaire. Quinze patients ont été inscrits dans chacun des deux volets de l'étude, et ce, jusqu'au terme de l'étude. L'âge moyen des patients était de 64 ans pour le groupe traité et de 71 pour le groupe témoin.

MESURES PARAMÉTRIQUES : Les mesures paramétriques ont été la consommation d'analgésiques, le rétablissement de l'amplitude de mouvement du genou et l'évaluation à l'aide d'une échelle analogique visuelle. RÉSULTATS : Aucune différence significative n'a été notée sur le plan du recours à l'analgésie, de l'amplitude de mouvement, de la durée du séjour hospitalier ou de l'évaluation obtenue à l'aide de l'échelle analogique visuelle. L'emploi total moyen de morphine a été de $148 \mathrm{mg}$ dans le groupe sous neurostimulation électrique et de $108 \mathrm{mg}$ dans le groupe témoin. L'amplitude de mouvement au septième jour post-opératoire a été de $75,3^{\circ}$ dans le groupe sous neurostimulation et de $73,6^{\circ}$ dans le groupe témoin. La durée moyenne du séjour hospitalier a été de 9,5 jours dans le groupe sous neurostimulation et de 8,3 dans le groupe témoin.

Toronto East General and Orthopaedic Hospital, University of Toronto, Toronto, Ontario

Correspondence: Dr GL Maistrelli, Toronto East General and Orthopaedic Hospital, Suite G123, 825 Coxwell Avenue, Toronto, Ontario M4C 3E7. Telephone 416-469-6332, fax 416-469-6534

Received for publication September 25, 1997. Accepted February 25, 1998 
$\mathrm{T}$ otal knee arthroplasty is one of the most common surgical procedures in orthopedics today. In the current trend towards shortening lengths of stay and earlier mobilization, any method that offers the patient improved analgesia and earlier range of motion must be evaluated.

Several studies have looked at the various methods of improving postoperative recovery of patients from this surgery. Etches et al (1) reported that continuous administration of intravenous ketorolac in the acute postoperative period after total knee arthroplasty resulted in a $44 \%$ reduction of patient-controlled intravenous morphine use. Moiniche et al (2) found that continuous epidural bupivacaine/morphine for the first $48 \mathrm{~h}$ after total knee replacement or total hip replacement resulted in lower pain scores but no improvement in convalescence or hospital stay. A prospective study comparing continuous passive motion (CPM), CPM with transcutaneous electrical nerve stimulation (TENS) and CPM with continuous cooling pad found no significant difference in pain medication consumption with the addition of TENS treatment (3). Recently a new device, the Synaptic 2000 (The Synaptic Corporation, Colorado), has been developed based on synaptic electronic activation (SEA) technology. The device administers to the subject a continuous modified square wave form with a $40 \mathrm{~V}$, peak to peak output through disposable transcutaneous electrodes at a frequency of $30,000 \mathrm{~Hz}$. It is hypothesized that the signal induces a change in neurotransmitter release from neuronal synapses, similar to a TENS device (4). Based on the experience of one author with the device, a prospective randomized control trial was employed to determine the efficacy of the Synaptic 2000 device for postoperative pain in the total knee replacement population.

\section{PATIENTS AND METHODS}

A prospective randomized controlled study was designed to test the efficacy of the Synaptic 2000 device for postoperative pain. All patients underwent a primary cemented Genesis total knee arthroplasty (Smith \& Nephew) performed by the same surgeon. The study was designed to assign patients randomly into one of two arms. The purpose of the device was explained to all patients in the study, who consented to its use before inclusion. All patients enrolled in the study received identical postoperative care including physiotherapy by the same registered physiotherapist. All patients received intravenous patient-controlled analgesia (PCA) pumps using morphine postoperatively and then were converted to oral analgesics as appropriate. The only difference between the two arms of the study was that one group received SEA treatments. The study looked at the effect of the device on pain as measured by analgesic consumption and range of motion in the operated knee.

The stimulating pads were placed on either side of the patient's knee that had been operated upon. Patients were then treated for 30 mins each weekday under the supervision of the physiotherapist. The range of motion measurements were taken by the same treating physiotherapist using a goniome-

\begin{tabular}{|c|c|c|c|c|c|c|c|c|}
\hline & \multirow{3}{*}{ Grp } & \multicolumn{7}{|c|}{ Analgesic use* } \\
\hline & & POD & POD & POD & POD & POD & POD & POD \\
\hline & & & & 3 & & 5 & & \\
\hline \multirow[t]{2}{*}{ Mean } & $\mathrm{Ctrl}$ & 45.87 & 24.60 & 10.87 & 4.94 & 6.00 & 6.50 & 8.75 \\
\hline & Treat & 56.21 & 34.31 & 13.57 & 7.76 & 11.64 & 11.73 & 12.55 \\
\hline \multirow[t]{2}{*}{ SD } & Ctrl & 33.33 & 22.64 & 10.58 & 5.10 & 5.13 & 6.37 & 4.88 \\
\hline & Treat & 27.55 & 26.77 & 8.23 & 5.32 & 10.23 & 10.06 & 7.96 \\
\hline $\begin{array}{r}\text { Studer } \\
t\end{array}$ & $\begin{array}{l}n t^{\prime} s \\
\text { est }\end{array}$ & 0.37 & 0.29 & 0.44 & 0.15 & 0.07 & 0.15 & 0.31 \\
\hline
\end{tabular}

*Values are converted equivalents of intravenous morphine in mg/day. Ctrl Control; Grp Group; POD Postoperative day; Treat Treatment

TABLE 2

Postoperative range of motion for the operated knee for both the control and treatment groups

\begin{tabular}{|c|c|c|c|c|c|c|c|}
\hline & \multirow[b]{3}{*}{ Group } & \multicolumn{6}{|c|}{ Range of motion* } \\
\hline & & POD & POD & POD & POD & POD & POD \\
\hline & & 2 & 3 & 4 & 5 & 6 & 7 \\
\hline \multirow[t]{2}{*}{ Mean } & Control & 39.83 & 51.25 & 66.50 & 65.00 & 68.50 & 73.57 \\
\hline & Treatment & 36.60 & 48.10 & 55.80 & 64.47 & 72.64 & 75.33 \\
\hline \multirow[t]{2}{*}{ SD } & Control & 12.81 & 12.50 & 11.71 & 17.71 & 15.10 & 7.46 \\
\hline & Treatment & 4.22 & 17.25 & 17.52 & 14.08 & 10.87 & 11.70 \\
\hline \multicolumn{2}{|c|}{ Student's $t$ test } & 0.60 & 0.67 & 0.16 & 0.93 & 0.46 & 0.73 \\
\hline
\end{tabular}

TABLE 3

Visual analogue pain scale measurements of patients' postoperative pain for both the control and treatment groups

\begin{tabular}{|cccccccccc}
\hline & \multicolumn{1}{c}{ Visual Analogue Pain Scale* } \\
& & POD & POD & POD & POD & POD & POD POD \\
Group & $\mathbf{1}$ & $\mathbf{2}$ & $\mathbf{3}$ & $\mathbf{4}$ & $\mathbf{5}$ & $\mathbf{6}$ & $\mathbf{7}$ \\
\hline Mean Control & 4.9 & 6.36 & 3.53 & 3.23 & 5.02 & 5.16 & 5.47 \\
& Treatment & 6.06 & 5.84 & 4.08 & 4.86 & 5.3 & 4.17 & 3.48 \\
SD & Control & 0.14 & 2.16 & 2.66 & 1.99 & 2.81 & 2.76 & 3.8 \\
& Treatment & 3.13 & 2.61 & 3.14 & 2.58 & 2.92 & 3.06 & 2.55 \\
Student's $t$ test & 0.64 & 0.74 & 0.77 & 0.29 & 0.81 & 0.43 & 0.23 \\
\hline *Values are a measurement of the pain along a 10 cm line, o being no \\
pain and 10 the worst pain in their life. POD Postoperative day
\end{tabular}

ter after the treatment session. Patients were also asked to mark on a visual analogue scale the amount of pain they had felt that day (patients were instructed on the use of the visual analogue scale before its use). All data were gathered by the treating physiotherapist.

Thirty patients were enrolled into the study and formed 
two groups of 15. A sample size calculation was not performed because the length of time that the device was made available for this trial was limited and not readily extendable. Data were collected in a prospective fashion for demographics, length of stay, analgesic use and knee range of motion. Data were analyzed by an independent observer who was blinded to the two groups. The initial analgesic used was intravenous PCA morphine. The patients were then converted to oral analgesics including acetaminophen/ caffeine/codeine phosphate (Tylenol \#3; Janssen-Ortho), acetaminophen/oxycodone hydrochloride (Percocet; DuPont Pharma), pentazocine hydrochloride (Talwin; Sanofi), pethidine hydrochloride (Demerol; Sanofi) and acetaminophen (Tylenol; McNeil Consumer Products). All analgesics were converted to an equivalence of intravenous morphine to facilitate comparison using a composite of equivalencies for single dose morphine (5-7). A two-tailed Student's $t$ test was used to determine the presence or absence of any difference between the two groups.

\section{RESULTS}

Fifteen patients randomly enrolled into each arm of the study. There were 10 women and five men in the control group and nine women and six men in the treatment group. Average age of patients in the control group was 71 years (range 37 to 85 ) and 64 years (range 46 to 78 ) in the treatment group, which was not statistically different. The average length of stay was 8.3 days in the control group and 9.5 days in the treatment group, also not statistically different. All patients were admitted on the day of surgery and discharged to a rehabilitation hospital for further recovery.

As can be seen from the analgesic consumption of the patients summarized in Table 1, for each of the postoperative days 1 through 7, the analgesic requirement for the treatment group was not statistically different from that for the control group. The total analgesic consumption over the first seven days after surgery was the equivalent of $108 \mathrm{mg}$ morphine for the control group and the equivalent of $148 \mathrm{mg}$ morphine for the treatment group. On postoperative day 2 the patient's plaster Jones bandage was removed from the operated knee, and mobilization was commenced using a standard protocol. The patient's range of motion was recorded starting on postoperative day 2 . There was no statistically significant difference in the range of motion between the two groups from days 2 through 7 (Table 2).

On postoperative day 3 patients were converted from PCA intravenous morphine to oral analgesics. The analgesic consumption for the first two days was equivalent to $86.8 \mathrm{mg}$ morphine for the SEA group versus $70.5 \mathrm{mg}$ for the control group. The average score on the visual analogue scale for the SEA group was 4.0 versus 2.8 for the control group for the first two days, which was not significant. There was no significant difference in analgesic consumption or visual analogue scale score between the two groups for the first two days when patients were switched from PCA to oral analgesics.

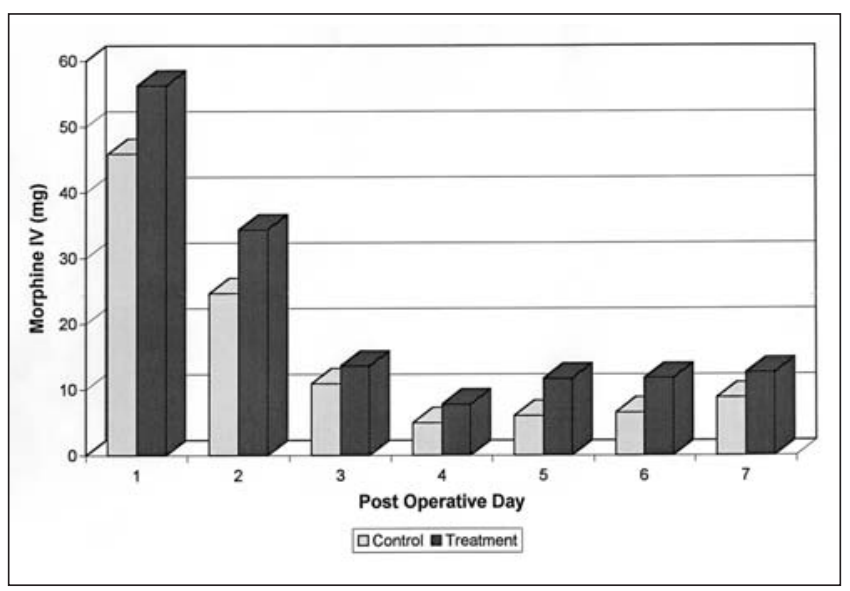

Figure 1) Daily analgesic consumption for both control and treatment groups. IV Intravenous

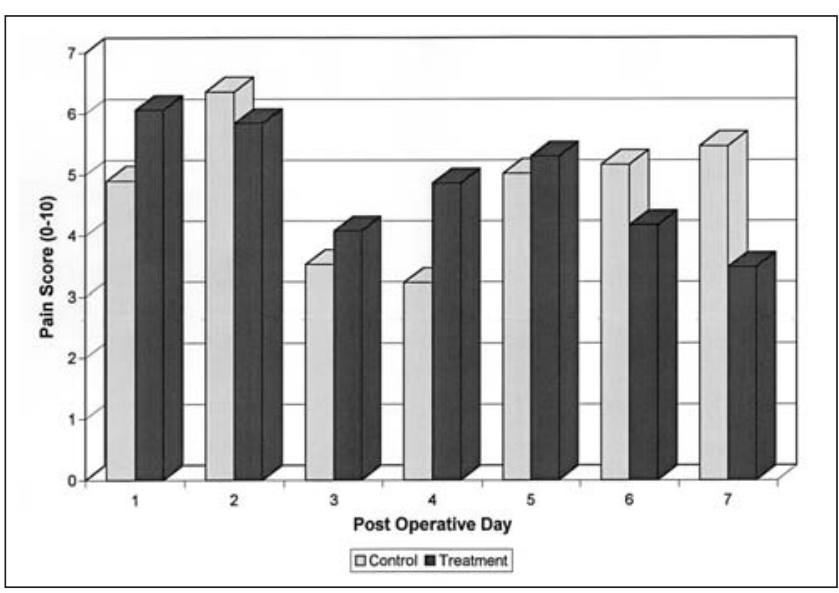

Figure 2) Visual analogue pain score for both the control and treatment groups

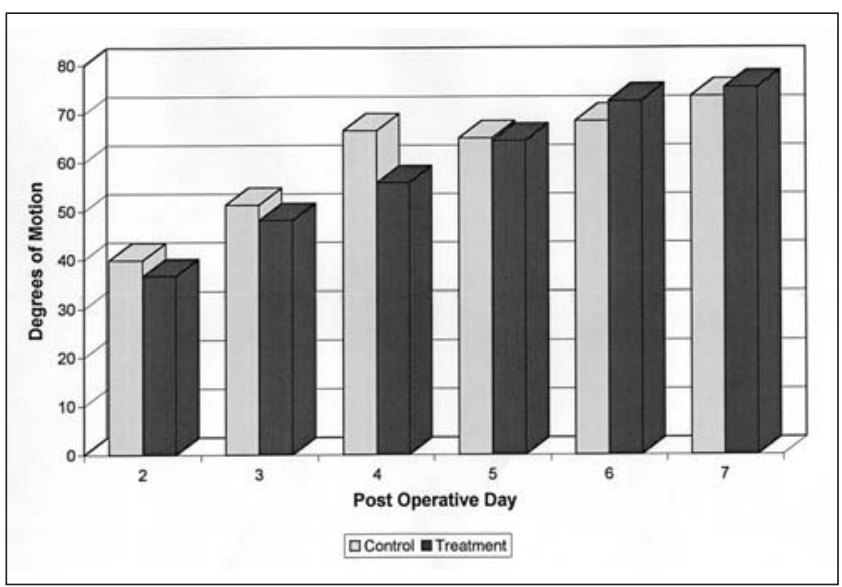

Figure 3) Postoperative total knee replacement range of motion for both the control and treatment groups

Patients' visual analogue scale measurements are presented in Table 3 . Due to the variability between individual pain perceptions, there was no significant difference between the control and treatment groups. 


\section{DISCUSSION}

Both groups of patients had similar demographics. The two groups did not differ significantly with respect to age, sex or side of surgery. The treatment group was slightly younger in age, which, if anything, might result in a greater range of motion and less analgesic requirement than the control group.

The treatment group required more analgesics than the control group, although this difference was not statistically significant. It was hypothesized that such a device should lead to a reduction in the amount of pain perceived by patients and, thus, the amount of analgesics required in the acute postoperative period. Surprisingly, the analgesic consumption showed a nonsignificant but apparent trend towards increased analgesic consumption in the group treated with the device, to the equivalent of $148 \mathrm{mg}$ morphine compared with the equivalent of $108 \mathrm{mg}$ in the treatment group (Figure 1). The visual analogue pain scores were also not statistically different between the two groups (Figure 2).

The anticipated benefit of a faster recovery of the operated knee's range of motion was not realized. The range of motion between the two groups was not statistically different for any of the postoperative days 2 through 7 (Figure 3). The length

\section{REFERENCES}

1. Etches RC, Warriner CB, Badner N, et al. Continuous intravenous administration of ketorolac reduces pain and morphine consumption after total hip or knee arthroplasty. Anesth Analg 1995;81:1175-80.

2. Moiniche S, Hjortso NC, Hansen BL, et al. The effect of balanced analgesia on early convalescence after major orthopaedic surgery. Acta Anaesthesiol Scand 1994;38:328-35.

3. Walker RH, Morris BA, Angulo DL, Schneider J, Colwell CW Jr. Postoperative use of continuous passive motion, transcutaneous electrical nerve stimulation, and continuous cooling pad following total knee arthroplasty. J Arthroplasty 1991;6:151-6.

4. Silverstone LM. The use of a new, non-invasive, neuromodulation of stay was also not significantly different between the two groups. However, it must be remembered that the findings relate to the first seven postoperative days and the benefits of the device in the subsequent period are unknown.

The reason for the increased requirement of analgesics may lie in the mechanism of action of the Synaptic 2000 device. By transmitting electrical impulses to the patient's operated limb, the device may inadvertently stimulate muscles across the operated joint. This can result in more force being transmitted across a joint in which a recent arthrotomy has been performed, thereby increasing the inflammatory response in the soft tissues surrounding the joint.

\section{CONCLUSIONS}

Use of Synaptic 2000 device in the acute postoperative period for total knee arthroplasty does not appear to enhance the reduction of analgesic consumption or the rate of recovery for the operated knee range of motion.

ACKNOWLEDGEMENTS: The authors gratefully acknowledge the assistance of Heather Logan BSc Pharm in the preparation of this manuscript.

device in the treatment of acute and chronic pain. Presented at the Annual Meeting of the American Neuromodulation Society, Orlando, Florida, March 1996.

5. Scott JF. Cancer Pain: A Monograph on the Management of Cancer Pain. Ottawa: Ministry of Supply and Service Canada, 1984:21.

6. De Angelis C. Practical guide to the use of narcotics for the management of pain in the cancer patient - Part 2: Choice of route of administration, narcotic formulation and dosing strategy. Focus Lit (MetroDIS) 1991;10:32.

7. Gillis MC, ed. Compendium of Pharmaceuticals and Specialties, 31st edn. Ottawa: Canadian Pharmaceutical Association, 1996:910-3. 


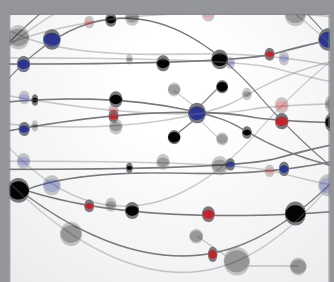

The Scientific World Journal
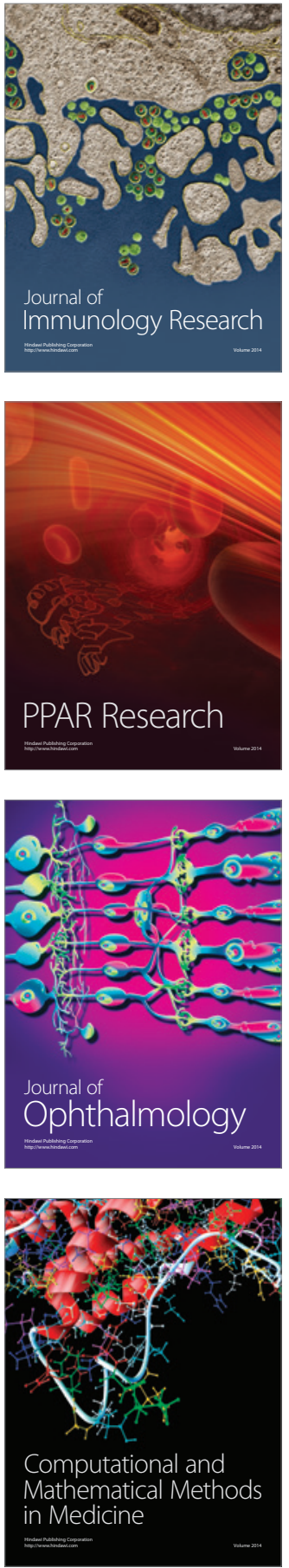

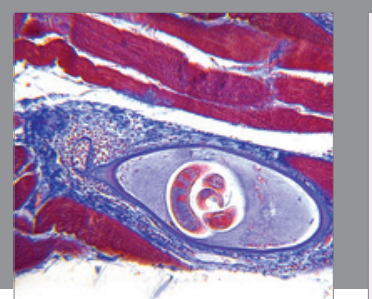

Gastroenterology Research and Practice

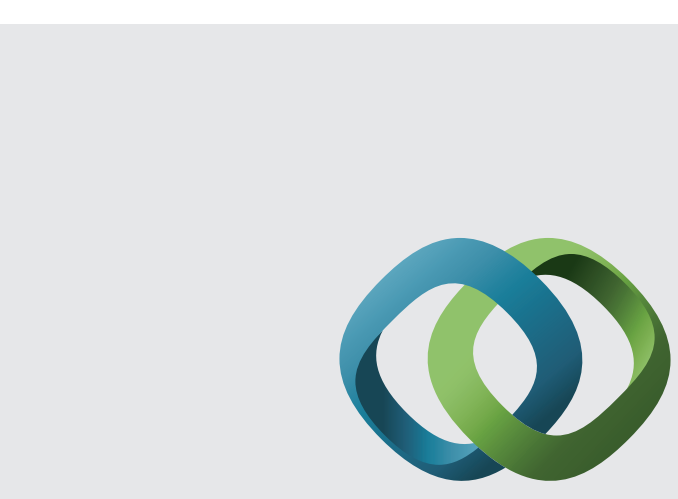

\section{Hindawi}

Submit your manuscripts at

http://www.hindawi.com
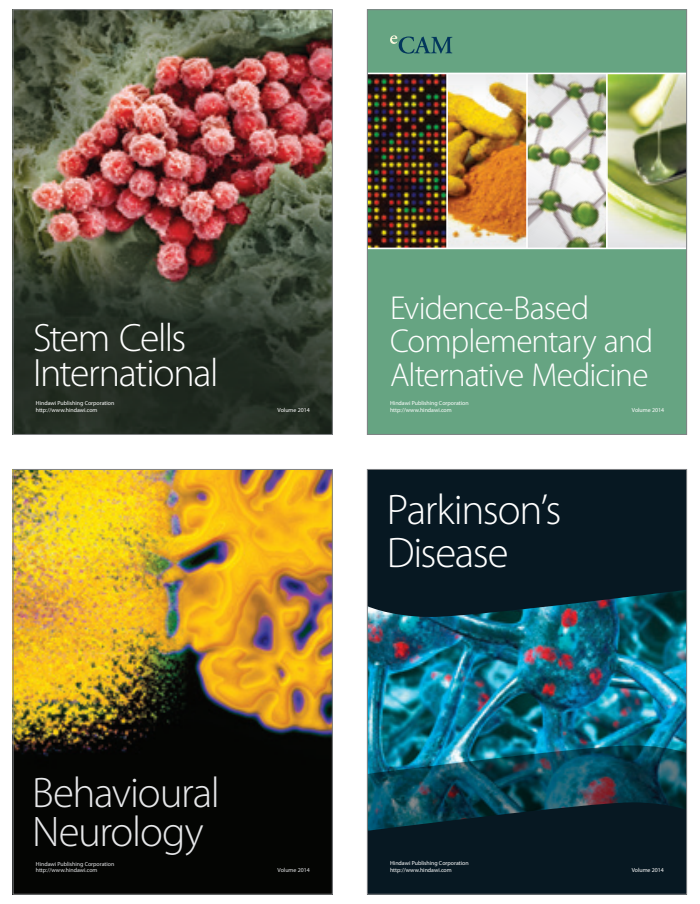
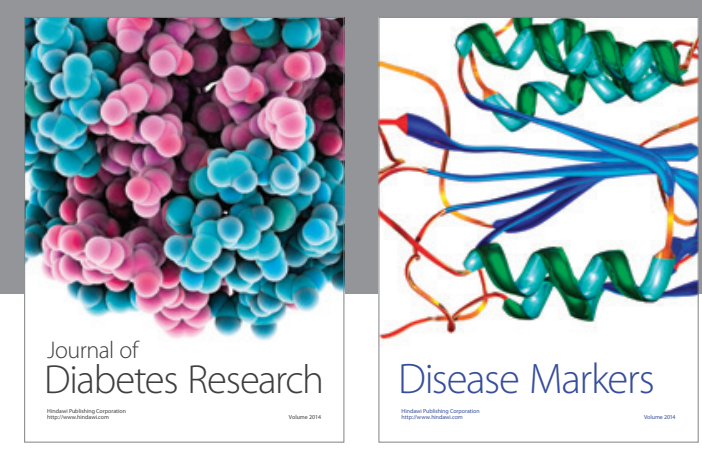

Disease Markers
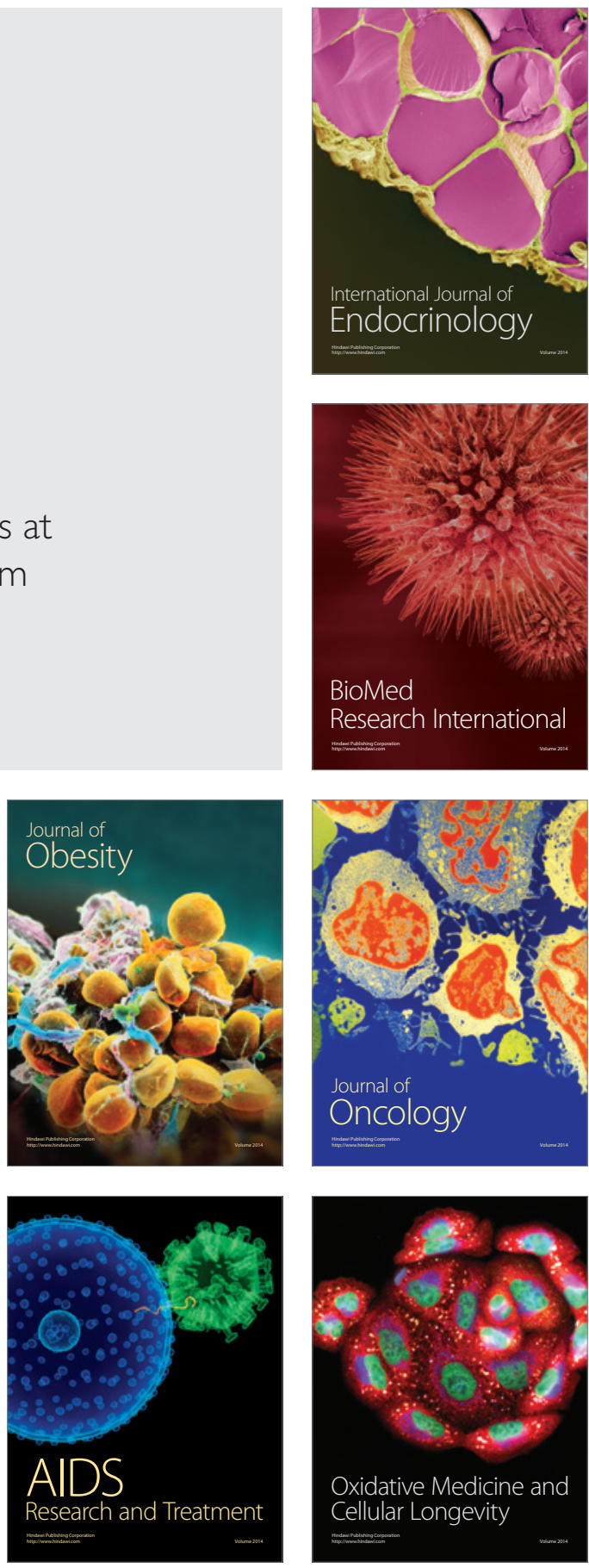